\title{
A New Animal Model to Study Endogenous Cardiotonic Steroids and the Progression of Cardiovascular Events in Salt-Sensitive Hypertension
}

\author{
Estela S Estape ${ }^{1 *}$, Ivette Torres-Negron ${ }^{2}$, Lorena Gonzalez ${ }^{3}$ and Manuel Martinez-Maldonado ${ }^{4}$
}

${ }^{1}$ School of Health Professions, Medical Sciences Campus, University of Puerto Rico, Puerto Rico

${ }^{2}$ School of Environmental Affairs, Universidad Metropolitana, Ana G Méndez University System, Puerto Rico

${ }^{3}$ Puerto Rico Clinical and Translational Research Consortium, Medical Sciences Campus, University of Puerto Rico, Puerto Rico

${ }^{4}$ Consultant, University of Puerto Rico, Medical Sciences Campus, Puerto Rico Clinical and Translational Research Consortium, Puerto Rico

${ }^{*}$ Corresponding author: Estela S. Estape, MT, PhD, DHL, Professor and Director/PI, Clinical and Translational Research Development Programs MSc \& HiREC, School of Health Professions, University of Puerto Rico-Medical Sciences Campus, GPO Box 365067, San Juan, PR 00936, Puerto Rico, Tel: 787-414-0523, E-mail: estela.estape@upr.edu

\begin{abstract}
The Dahl salt-sensitive rat is a well-established model to study essential hypertension. We first described a subgroup of these rats based on the unique response pattern in systolic blood pressure during the first weeks of exposure to a high salt diet that included cataract formation. We classified this group as cataractprone Dahl salt-sensitive rat. We also were able to predict and prevent cataract formation in these rats. Further studies showed an inhibition of lens $\mathrm{Na}$, K-ATPase activity which may be in part responsible for the cataract formation. Other studies in Dahl saltsensitive rats maintained on a high salt diet have also shown decreased $\mathrm{Na}$, K-ATPase activity in several tissues and increased levels of endogenous circulating $\mathrm{Na}, \mathrm{K}$ pump inhibitors. For over 20 years, endogenous cardiotonic steroids have been postulated to inhibit $\mathrm{Na}$, K-ATPase in both humans as well as in experimental animal models of hypertension. Recent findings have shown results suggesting that there are several forms of cardiotonic steroids with minor differences in structural functionalities, site of production, and specific pump selectivity. We present original data that supports a role for cardiotonic steroids in disease progression related to increased salt-sensitivity. We found increased levels of free endogenous cardiotonic steroids in those rats that were classified as cataract-prone according to their initial systolic blood pressure response to a high salt intake when compared to noncataract prone Dahl salt-sensitive rats and their control Dahl saltresistant rats. The cataract-prone Dahl salt-sensitive rat is an animal model that can help and contribute to open a new door to possibly elucidate the role of endogenous cardiotonic steroids in the pathogenesis and progression of diseases related to saltsensitive hypertension.
\end{abstract}

\section{Keywords}

Cardiac glycosides, Cardiovascular diseases, Endogenous cardiotonic steroids, Hypertension, Animal models, Salt-sensitivity, Stroke

\section{Introduction}

The Dahl salt-sensitive (DS) rat is a known experimental model of salt-sensitive, volume expansion essential hypertension [1]. We found that approximately $35 \%$ of weanling DS maintained on a high salt diet until adulthood had an increased incidence of anterior cortical cataract formation suggesting a possible ion transport defect [2]. The group of rats that developed cataracts were those DS that had an initial higher systolic blood pressure response (SBP) during the first four (4) weeks on a high salt intake. These rats were classified as cataract-prone DS (DSc). Rats that did not conform to the unique SBP response found in DSc were classified as DS unlikely to develop cataracts (DSnc) [2-4]. Intermediate responders were not studied further. Cataractous lesions in the DSc were characterized by marked lenticular and aqueous humor electrolyte imbalance [2]. We then studied the effect of a chronic high sodium diet starting in weanling rats on lenticular ouabain- sensitive Rubidium uptake in DS and Dahl salt-resistant (DR) rats as an index of lenticular $\mathrm{Na}$, K'ATPase activity [3]. The decrease in total lens Rubidium uptake in DSc before cataract formation was the result of only decreased ouabain-sensitive uptake suggesting that decreased lenticular $\mathrm{Na}$, K-ATPase activity might precede cataract formation.

Cognizant of the different genetic profiles of the rat strains and their subsequent variable response to salt intake, we used SpragueDawley (SD) rats from which DS and salt resistant (DR) rats were genetically derived, to characterize active and passive $\mathrm{Na}^{+}$and $\mathrm{K}^{+}$ transport with the use of the short-circuiting technique in the rat lens during chronic normal $\mathrm{NaCl}$ diet [5]. We then studied the effect of normal vs high $\mathrm{NaCl}$ chronic intake in the lens of $\mathrm{SD}$ weanling rats up to 26-30 weeks of age [6]. Although neither sustained hypertension nor cataract formation was observed in any SD rats, the basal lens electrical parameters (lens short-circuit current, translenticular potential and resistance) were significantly altered by

\section{CIinMed International Library}

Citation: Estape ES, Torres-Negron I, Gonzalez L, Maldonado MM (2015) A New Animal Model to Study Endogenous Cardiotonic Steroids and the Progression of Cardiovascular Events in Salt-Sensitive Hypertension. Int Arch Transl Med 1:002

Received: March 12, 2015: Accepted: May 28, 2015: Published: May 30, 2015 Copyright: ( 2015 Estape ES. This is an open-access article distributed under the terms of the Creative Commons Attribution License, which permits unrestricted use, distribution, and reproduction in any medium, provided the original author and source are credited. 
high $\mathrm{NaCl}$ intake. A similar study was done to evaluate the effect of chronic normal vs high $\mathrm{NaCl}$ intake in the lens of DSc, DSnc and DR rats [7]. All short circuit current measurements in DSc were done in transparent lenses assessed through slit-lamp microscopy. Although DSnc had significantly decreased lenticular values when compared to DR, we found significantly lower levels in DSc when compared to DSnc. These data suggests that cataractogenesis in DSc may depend on the degree of salt-sensitivity and that lenticular $\mathrm{Na}$, K-ATPase inhibition may play a pivotal role in the loss of transparency of the lens.

For over 20 years, several forms of endogenous cardiotonic steroids (CTS) have been postulated to inhibit $\mathrm{Na}$, K-ATPase in both humans as well as in experimental animal models of hypertension. We decided to conduct this preliminary study to determine if DS and DR rats kept on a chronic high salt diet had different levels of endogenous cardiotonic steroids. Endogenous digitalis like substances (for the purpose of this study it will be abbreviated DLIF) was one of the first cardiotonic steroids (CTS) to be found in plasma of volume-expanded dogs [8], in newborns, pregnant women and in renal failure [9], human cataractous lenses [10], diabetic women with preeclampsia [11]; it was also proposed to be a determinant of salt balance and intracellular sodium in hypertension [12]. Endogenous CTS encompass various chemically similar compounds that have in common a steroid structure and may inhibit or modulate the activity of the $\mathrm{Na}$, K-ATPase, including ouabain-like substances in hypertension [13], bufodienolide in acute myocardial infarction [14], and telocinobufagenin in terminal renal failure [15]. Although the existence and effects of these endogenous cardiotonic steroids has been extensively studied and discussed [13,16-18], recent published articles reconfirm the complex nature of CTS [19-22].

Taking into consideration our previous findings suggesting a link between degree of salt sensitivity, rapid onset of hypertension and decreased lenticular ionic flow in the cataract-prone DS rats (DSc) [2-7], we measured levels of serum Total and Free DLIF in DS and DR kept on a chronic high $\mathrm{NaCl}$ intake. The objective of this study was to evaluate if there was a possible link between increased levels of a circulating inhibitor of $\mathrm{Na}$, K-ATPase with the systolic blood pressure (SBP) response and the prediction of cataract formation in the DS rat. The results described in this article are part of studies performed in our laboratory at the Puerto Rico Veteran Administration Medical Center (VAMC), presented and published as an abstract in 1997 [23] Although we fully recognize the existence of other technology to study the complex nature of CTS, we consider that the use of digoxin polyclonal antibodies has the ability to recognize multiple epitopes on any one antigen $[24,25]$. Therefore, although not as robust for quantitative CTS experiments, the use of polyclonal antibodies exhibit higher affinity to help amplify the signal from targets with low expression level.

\section{Materials and Methods}

A total of 42 weanling female DS and 6 age- and sex-matched DR (both derived from Brookhaven outbred Dahl rats) were studied under conditions previously described [2-7]. Animals were fed a standard chow diet (Purina Mills; $0.4 \%$ sodium, $0.65 \%$ chloride and tap water). SBP was determined in conscious rats at the age of 4-5 weeks as well as throughout the experiments, using the technique of tail-cuff plethysmography. All SBP values were expressed as the mean value of 10 consecutive measurements. With the use of this technique we can only measure SBP, which according to the Seventh Report of the Joint National Committee on Prevention, Detection, Evaluation, and Treatment of High Blood Pressure), systolic blood pressure is a more important cardiovascular disease risk factor than diastolic blood pressure [26]. After measurement of basal SBP, all rats were offered the same normal sodium diet but tap water was substituted with $0.9 \% \mathrm{NaCl}$ (high salt intake) ad libitum. This dietary regimen was maintained throughout the length of the study.

DS that had a marked increase in SBP after one week on a high salt diet and steadily increased over the next 3 weeks, reaching SBP measurements over $160 \mathrm{mmHg}$ by the end of 4 weeks on a high salt diet were classified as DSc. DSnc were classified as those DS that, after one week on a high salt diet, had a SBP value less than $130 \mathrm{mmHg}$ and less than $160 \mathrm{mmHg}$ by the end of 4 weeks on the high salt diet. As previously reported, the DS rats that were not constant in their SBP response to high salt diet were classified as intermediate and were not studied further $[3,4]$. Of the 42 DS rats, 6 rats died before reaching 11 weeks (wks) of age. SBP measurements were performed before rats were sacrificed and blood was collected for DLIF analysis. DLIF analysis for the DSc group $(\mathrm{n}=6)$ was done at 11 wks of age (7 wks on high salt diet) with corresponding DR controls $(n=6)$. DSnc rats $(n=5)$ were studied at $17 \mathrm{wks}$ of age ( $13 \mathrm{wks}$ on high salt), a time when they reached similar SBP level as the DSc group.

All studies were approved by the local Institutional Review Board and complied with the National Institute of Health Publication Guide for the Care and Use of Laboratory Animals. Serum was used to determine DLIF levels by radioimmunoassay (RIA) technique as described previously [9]. The magnitude of digoxinlike immunoactivity was measured by competitive displacement of $\left[{ }^{125} \mathrm{I}\right]$-digoxin from antidigoxin antibodies relative to digoxin standards. The components for this assay were obtained from New England Nuclear (Billerica, MA). The primary antiserum was rabbit antidigoxin antiserum prereacted with goat antiserum to rabbit $\gamma$-globulin (second antibody). This was a commercially available double antibody radioimmunoassay (Du Pont-New England Nuclear). The labeled tracer material was $\left[{ }^{125} \mathrm{I}\right]$-histamine-digoxin. The standards were pure digoxin in normal human serum, ranging in concentration from 25-2000 picograms per milliliter ( $\mathrm{pg} / \mathrm{ml}$ ). Levels measured directly in serum by RIA represented the Free DLIF (unbound fraction). Heating the serum $\left(5 \mathrm{~min}\right.$ at $\left.100^{\circ} \mathrm{C}\right)$, provided an estimate of Total DLIF [9].

The statistical relationship between levels of DLIF, at the end of 7 weeks and 13 weeks in the high salt diet, and the type of rats (DSc,

Table 1: Systolic Blood Pressure of rats with a high salt diet intake

\begin{tabular}{|c|c|c|c|c|}
\hline \multirow{2}{*}{$\begin{array}{l}\text { Time with high salt intake } \\
\text { diet }\end{array}$} & \multicolumn{3}{|c|}{ Type of Rats } & \multirow[b]{2}{*}{ P-value ${ }^{a}$} \\
\hline & DSc $(n=6)$ & DSnc $(n=5)$ & DR $(n=6)$ & \\
\hline \multicolumn{5}{|l|}{0 Weeks (Basal) } \\
\hline Mean ( \pm SD) & $108.7(11.6)$ & $105.8(8.6)$ & $115.5(3.9)$ & 0.13 \\
\hline Median & 114.5 & 101.0 & 116.5 & \\
\hline Min, Max & 89,119 & 98,117 & 108,119 & \\
\hline \multicolumn{5}{|l|}{1 Week $^{b}$} \\
\hline Mean $( \pm S D)$ & $140.2(17.4)$ & $130.6(16.3)$ & $130.4(8.7)$ & 0.37 \\
\hline Median & 135.0 & 127.0 & 127.0 & \\
\hline Min, Max & 122,170 & 118,158 & 122,142 & \\
\hline \multicolumn{5}{|l|}{2 Weeks } \\
\hline Mean $( \pm S D)$ & $176.5(17.1)$ & $154.2(11.2)$ & $129.0(10.8)$ & $<0.01$ \\
\hline Median & 184.5 & 153.0 & 126.5 & \\
\hline Min, Max & 154,190 & 144,173 & 118,147 & \\
\hline \multicolumn{5}{|l|}{3 Weeks } \\
\hline Mean $( \pm S D)$ & $184.8(12.9)$ & $149.4(15.6)$ & $125.2(6.8)$ & $<0.01$ \\
\hline Median & 181.5 & 152.0 & 123.0 & \\
\hline Min, Max & 167,204 & 124,165 & 118,135 & \\
\hline \multicolumn{5}{|l|}{4 Weeks } \\
\hline Mean $( \pm \mathrm{SD})$ & $182.2(11.3)$ & $151.6(4.2)$ & $129.7(12.1)$ & $<0.01$ \\
\hline Median & 181.5 & 150.0 & 127.0 & \\
\hline Min, Max & 170,195 & 149,159 & 119,153 & \\
\hline \multicolumn{5}{|l|}{7 Weeks $^{c}$} \\
\hline Mean ( \pm SD) & $228.5(14.0)$ & $173.0(35.8)$ & $127.0(9.2)$ & $<0.01$ \\
\hline Median & 231.5 & 163.0 & 127.0 & \\
\hline Min, Max & 204,241 & 143,235 & 114,138 & \\
\hline \multicolumn{5}{|l|}{13 Weeks $^{d}$} \\
\hline Mean $( \pm S D)$ & - & $202.2(25.0)$ & - & $\mathrm{n} / \mathrm{a}$ \\
\hline Median & - & 202.0 & - & \\
\hline Min, Max & - & 172,241 & - & \\
\hline
\end{tabular}

Note: DSc: Cataract-prone Dahl Sensitive rats; DSnc: Dahl Sensitive unlikely to develop cataracts; DR: Dahl Resistant; ${ }^{a}$ Kruskal-Wallis test was used to determine significance $(P<0.05)$; ${ }^{b}$ One missing value for the DR group; ' $D S c$ and DR rats were killed at 7 -weeks of receiving a high salt diet; ${ }^{d} D S n c$ rats were killed at 13-weeks of receiving a high salt diet 


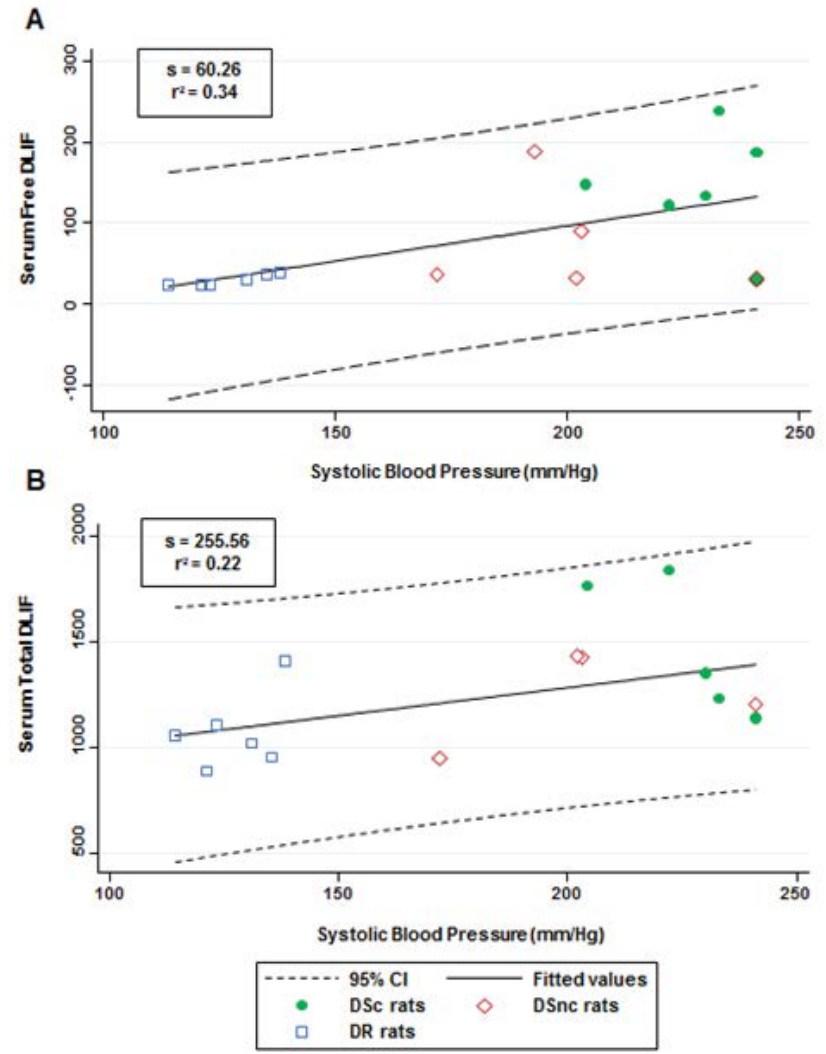

Figure 1: Association between Serum DLIF values and systolic blood pressure by rat groups. Specifically, figure $1 \mathrm{~A}$ for Serum Free DLIF and $1 \mathrm{~B}$ for Serum Total DLIF.

DSnc, and DR) was assessed using the Kruskal-Wallis test. This test was also used to assess weekly differences in SBP distribution among the rats on a high salt diet. We assessed possible interaction effect between the type of rats and weeks on a high salt diet. If a statistical significant difference was found using the Kruskal-Wallis test, then a Mann-Whitney $U$ test was performed using a Bonferroni correction to determine which of the groups were significantly different; $\mathrm{p}$-values $<0.017$ were considered statistically significant. Furthermore, based on results obtained at the moment of death of the rats, a simple linear regression analysis was performed in order to assess the relationship between SBP (predictor) and levels of DLIF (outcome).

\section{Results}

Table 1 shows the SBP for each group of rats according to weeks of exposure to a high salt diet. Significant statistical interactions were found between SBP and weeks on a high salt diet $(\mathrm{P}<0.05)$. After twoweeks on a high salt diet, the SBP distribution differed between types of rats $(\mathrm{P}<0.05)$; DSc and DSnc rats after two weeks of a high salt diet, were more likely to have a greater median $\mathrm{SBP}$ than $\mathrm{DR}$ rats $(\mathrm{P}=0.010$ and $\mathrm{P}=0.004$, respectively).

Table 2 shows Total and Free serum DLIF values for each group of rats. Differences in Free DLIF were observed among the three groups $(\mathrm{P}<0.02)$. By contrast, Total DLIF did not differ statistically among groups $(\mathrm{P}>0.05)$. DSc rats were more likely to have higher levels of serum Free DLIF than DR rats (median values $142 \mathrm{pg} / \mathrm{ml}$ vs. $28 \mathrm{pg} / \mathrm{ml}$; $\mathrm{P}=0.010$ ) and $\mathrm{DSnc}$ rats (median value $38 \mathrm{pg} / \mathrm{ml}$ ).

Figure $1 \mathrm{~A}$ and $1 \mathrm{~B}$ shows the association between Free and Total DLIF, respectively, and SBP. About $34 \%$ of the variability observed in serum Free DLIF and $22 \%$ of the variability in Total DLIF can be explained by measuring the SBP levels. For every additional $\mathrm{mm} / \mathrm{Hg}$ in SBP, we found Free DLIF to increase significantly by an average of $0.87 \mathrm{pg} / \mathrm{ml}(\mathrm{P}=0.02)$. Serum Total DLIF in all rats increased, although not significantly $(\mathrm{P}=0.07)$, by an average of $2.61 \mathrm{pg} / \mathrm{ml}$ for every additional $\mathrm{mm} / \mathrm{Hg}$ in SBP. It is clear from Figure $1 \mathrm{~A}$ that the higher the level of SBP, the higher the level of Free DLIF. Such a correlation
Table 2: Serum DLIF values for each group of rats at the moment of death

\begin{tabular}{|c|c|c|c|c|}
\hline \multirow{2}{*}{$\begin{array}{c}\text { Serum } \\
\text { DLIF pg/ml }\end{array}$} & \multicolumn{3}{|c|}{ Type of Rat } & \multirow[b]{2}{*}{ P-value } \\
\hline & $\begin{array}{c}\text { DSc } \\
(n=6)\end{array}$ & $\begin{array}{l}\text { DSnc } \\
(n=5)\end{array}$ & $\begin{array}{c}\text { DR } \\
(n=6)\end{array}$ & \\
\hline \multicolumn{5}{|l|}{ Total } \\
\hline $\begin{array}{c}\text { Mean } \\
( \pm \text { SD) }\end{array}$ & $\begin{array}{l}1411.8 \\
(314.3)\end{array}$ & $\begin{array}{c}1602.0 \\
(806.7)\end{array}$ & $\begin{array}{r}1071.9 \\
(181.4)\end{array}$ & 0.07 \\
\hline Median & 1293.7 & 1428.5 & 1037.4 & \\
\hline $\begin{array}{l}\text { Min } \\
\text { Max }\end{array}$ & $\begin{array}{l}1136.0 \\
1839.4\end{array}$ & $\begin{array}{l}946.4 \\
3000\end{array}$ & $\begin{array}{c}889.0 \\
1408.0\end{array}$ & \\
\hline \multicolumn{5}{|l|}{ Free } \\
\hline $\begin{array}{c}\text { Mean } \\
( \pm \text { SD) }\end{array}$ & $\begin{array}{l}144.0 \\
(69.5)\end{array}$ & $\begin{array}{c}76.4 \\
(68.1)\end{array}$ & $\begin{array}{l}30.2 \\
(6.3)\end{array}$ & 0.02 \\
\hline Median & 141.7 & 37.5 & 27.7 & \\
\hline $\begin{array}{l}\text { Min } \\
\text { Max }\end{array}$ & $\begin{array}{c}31.4 \\
239.3\end{array}$ & $\begin{array}{l}31.5 \\
190\end{array}$ & $\begin{array}{l}25.0 \\
38.7\end{array}$ & \\
\hline
\end{tabular}

Note: DSc: Cataract-prone Dahl Sensitive rats; DSnc: Dahl Sensitive unlikely to develop cataracts; DR: Dahl Resistant; ${ }^{a}$ Kruskal-Wallis test was used to determine significance $(P<0.05)$.

did not hold for Total DLIF.

\section{Discussion}

Establishing criteria for animal models to be used in cardiovascular disease is a challenging goal due to the complex multifactorial nature of the disease. It has been suggested that an ideal animal model of cardiovascular disease would be one that mimics the human subject metabolically and pathophysiologically, is large enough to permit physiological and metabolic studies, and will develop end-stage disease comparable to those in humans [27]. We agree with the conclusions of Russell JC \& Proctor SD [27] that:

- no one species will be suitable for all studies,

- the most useful and valid species/strains for the study of cardiovascular disease appear to be small rodents, rats, and mice,

- this fragmented field would benefit from a consensus on wellcharacterized appropriate models for the study of different aspects of cardiovascular disease and a renewed emphasis on the biology of underlying diseases

Thus, our rat model is eligible to be used for the study of the relationships among high blood pressure dependent on salt intake, DLIF and cataracts. Varying blood pressure responses to a high salt intake observed in DS has also been demonstrated in clinical studies. When switched from a lower to a higher $\mathrm{NaCl}$ diet, increases in salt sensitivity in blood pressure responses were observed in healthy and hypertensive individuals [28-31]. Increased salt-sensitivity has also been shown to be race-related. For example, blacks have a greater frequency of salt sensitivity than whites and a more aggressive hypertension progression leading to increased complications and mortality [28,32-34].

Our results analyzed by linear regression revealed a significant correlation between increased SBP and Free DLIF. No such correlation could be established for Total DLIF, suggesting that the major change in DLIF with increased SBP can be due to a shift of the Bound DLIF (attached to proteins or inactive) fraction to the free (active) DLIF fraction. In addition, it is important to note that serum Total DLIF was increased in all rats in response to the high salt diet with no significant differences among groups. This finding strengthens the suggestion that the significant changes in SBP and, therefore, the consequences of hypertension in this model correlate best with Free circulating DLIF.

With the exception of our studies with DSc and DSnc rats, to our knowledge all published experiments in salt sensitive rats bred from Brookhaven have used the DS rat as a single study group. As a result, minor but significant changes and higher mortality rate in the DSc subgroup in response to a high salt diet might have been overlooked or unnoticed [35]. This is also observed in humans, where approximately $60 \%$ of all hypertensive subjects are salt-sensitive and among them there is variability in their salt-sensitivity response to high salt. In the 
present study, we found higher levels of Free circulating CTS in DSc before cataract formation when compared to DSnc and DR.

There have been numerous basic and clinical research studies focusing on the interactions between different forms of endogenous CTS and the complications of cardiovascular diseases related to hypertension and salt-sensitive hypertension. Our preliminary results in the DS rats exposed to a high salt diet support the evidence suggesting that CTS may be of crucial importance in the high mortality rate associated with increased blood pressure response, salt sensitivity and renal salt handling $[17,36]$. Considering that high blood pressure is the number one cardiovascular risk factor for cardiac failure and stroke, $[37,38]$ we propose the DSc rat as an experimental model to study these relationships and further define the role of endogenous cardiotonic steroids as potential early diagnostic biomarkers to identify those individuals who are at higher risk.

In summary, based on extensive studies in our laboratory [2-7] we suggest that the DSc together with DSnc and DR can be used as a new animal model, where the beginning and progression of diseases related to salt-sensitivity and blood pressure can be studied before the onset of pathological findings. It is important for other organ involvement studies in this model that we were able to predict and prevent cataract formation in the DSc rats [39] and showed low plasma renin activity and increased ouabain-sensitive lenticular Rubidium uptake in weanling DSc before the development of sustained hypertension and cataracts [40]. This new model can provide important information that may help elucidate cardiovascular mechanisms or biomarkers for early diagnosis, prevention or treatment of high-risk individuals. The following highlights aim to provide the readers with a quick overview of our core findings:

- DS rats have different salt sensitivities (blood pressure response) when exposed to a high salt diet

- Total DLIF was the same independent of the blood pressure response to high salt

- DS rats with rapid onset of hypertension (DSc) had higher Free DLIF levels

In conclusion, the DSc model may help to expand and strengthen our knowledge of the relationship of salt sensitivity of blood pressure as have been discussed in recent studies and reviews [17,18,36,4043]. Moreover, the DSc model can help advance knowledge of the pathophysiology of ocular pathology in ageing [44].

\section{Acknowledgements}

We are grateful to Dr. Carmen Rodríguez-Sargent for her participation in the design of these experiments; Dr. Roland Valdes for providing the Digoxin antibody and methodology; Dr. Adolfo Firpo for his suggestions; and to Dr. Mary Helen Mays who reviewed early versions of the manuscript.

\section{Sources of Funding}

Merit Review funds of the Department of Veterans Affairs, RR 03051 and the National Institute on Minority Health and Health Disparities of the National Institutes of Health 2U54MD007587.

\section{References}

1. Dahl LK, Knudsen KD, Heine MA, Leitl GJ (1968) Effects of chronic excess salt ingestion. Modification of experimental hypertension in the rat by variations in the diet. Circ Res 22: 11-18.

2. Rodríguez-Sargent $\mathrm{C}$, Cangiano JL, Berríos Cabán G, Marrero E, MartínezMaldonado M (1987) Cataracts and hypertension in salt-sensitive rats. A possible ion transport defect. Hypertension 9: 304-308.

3. Rodríguez-Sargent C, Estapé-Wainwright E, Cangiano JL, Irizarry JE Martínez-Maldonado M (1988) Lenticular rubidium uptake in hypertensive 'cataract-prone' salt-sensitive rats. J Hypertens: 272-275.

4. Rodríguez-Sargent C, Berrios G, Irrizarry JE, Estapé ES, Cangiano JL, et al. (1989) Prevention and reversal of cataracts in genetically hypertensive rats through sodium restriction. Invest Ophthalmol Vis Sci 30: 2356-2360.

5. Estapé ES, Rodríguez-Sargent C, Candia OA (1992) Characterization of active and passive $\mathrm{Na}+$ and $\mathrm{K}+$ transport in normal rat lens by the shortcircuiting technique. Curr Eye Res 11: 189-193.
6. Estapé ES, Rodríguez-Sargent C, Cangiano JL, Candia OA (1995) Increased dietary $\mathrm{NaCl}$ intake influences lens transport properties in Sprague-Dawley rats. Curr Eye Res 14: 159-162.

7. Rodríguez-Sargent $\mathrm{C}$, Estapé ES, Fernández N, Irizarry JE, Cangiano JL, et al. (1996) Altered lens short-circuit current in adult cataract-prone Dahl hypertensive rats. Hypertension 28: 440-443.

8. Gruber KA, Whitaker JM, Buckalew VM Jr (1980) Endogenous digitalis-like substance in plasma of volume-expanded dogs. Nature 287: 743-745.

9. Valdes R Jr, Graves SW (1985) Protein binding of endogenous digoxinimmunoactive factors in human serum and its variation with clinical condition. J Clin Endocrinol Metab 60: 1135-1143.

10. Lichtstein D, Gati I, Samuelov S, Berson D, Rozenman Y, et al. (1993) Identification of digitalis-like compounds in human cataractous lenses. Eur $\mathrm{J}$ Biochem 216: 261-268.

11. Graves SW, Lincoln K, Cook SL, Seely EW (1995) Digitalis-like factor and digoxin-like immunoreactive factor in diabetic women with preeclampsia, transient hypertension of pregnancy, and normotensive pregnancy. Am J Hypertens 8: 5-11.

12. Haddy FJ (1990) Digitalislike circulating factor in hypertension: potential messenger between salt balance and intracellular sodium. Cardiovasc Drugs Ther 4 Suppl 2: 343-349.

13. Hamlyn JM1, Blaustein MP (2013) Salt sensitivity, endogenous ouabain and hypertension. Curr Opin Nephrol Hypertens 22: 51-58.

14. Bagrov AY, Fedorova OV, Dmitrieva R, Howald WN, Hunter AP, et al. (1998) Characterization of a urinary bufodienolide $\mathrm{Na}+, \mathrm{K}+-\mathrm{ATP}$ ase inhibitor in patients after acute myocardial infarction. Hypertension 31: 1097-1103.

15. Komiyama Y, Dong XH, Nishimura N, Masaki H, Yoshika M, et al. (2005) A novel endogenous digitalis, telocinobufagin, exhibits elevated plasma levels in patient with terminal renal failure. Clin Biochem 38: 36-45.

16. Fedorova OV, Shapiro JI, Bagrov AY (2010) Endogenous cardiotonic steroids and salt-sensitive hypertension. Biochim Biophys Acta 1802: 1230-1236.

17. Khundmiri SJ (2014) Advances in understanding the role of cardiac glycosides in control of sodium transport in renal tubules. J Endocrinol 222: R11-24.

18. Dial L, Liu J, Shapiro JI1 (2014) Cardiotonic steroids in adaptation to dietary salt intake. Curr Clin Pharmacol 9: 298-309.

19. Lewis LK, Yandle TG, Hilton PJ, Jensen BP, Begg EJ, et al. (2014) Endogenous ouabain is not ouabain. Hypertension 64: 680-683.

20. Blaustein MP (2014) Why isn't endogenous ouabain more widely accepted? Am J Physiol Heart Circ Physiol 307: H635-639.

21. Baecher S, Kroiss M, Fassnacht M, Vogeser M (2014) No endogenous ouabain is detectable in human plasma by ultra-sensitive UPLC-MS/MS. Clin Chim Acta 431: 87-92.

22. Ghadhanfar E, Al-Bader M, Turcani M (2014) Wistar rats resistant to the hypertensive effects of ouabain exhibit enhanced cardiac vagal activity and elevated plasma levels of calcitonin gene-related Peptide. PLoS One 9:e108909.

23. Estapé E, Torres-Negrón I, Firpo A, Valdes R Jr (1997) Digoxin-like immunoreactive factor (DLIF): a potential marker for stroke- proneness? Therapeutic Drug Monitoring 19: 573.

24. Valdes R Jr (1985) Endogenous digoxin-like immunoreactive factors: impact on digoxin measurements and potential physiological implications. Clin Chem 31: 1525-1532.

25. Hamlyn JM, Harris DW, Ludens JH (1989) Digitalis-like activity in human plasma. Purification, affinity, and mechanism. J Biol Chem 264: 7395-7404.

26. (2003) National Heart, Lung, and Blood Institute. The Seventh Report of the Joint National Committee on Prevention, Detection, Evaluation, and Treatment of High Blood Pressure. Bethesda, Md: National Heart, Lung, and Blood Institute 03-5233.

27. Russell JC, Proctor SD (2006) Small animal models of cardiovascular disease: tools for the study of the roles of metabolic syndrome, dyslipidemia, and atherosclerosis. Cardiovasc Pathol 15: 318-330.

28. Wilson DK, Bayer L, Sica DA (1996) Variability in salt sensitivity classifications in black male versus female adolescents. Hypertension 28: 250-255.

29. Piccirillo G, Bucca C, Durante M, Santagada E, Munizzi MR, et al. (1996) Heart rate and blood pressure variabilities in salt-sensitive hypertension. Hypertension 28: 944-952.

30. Anderson DE, Fedorova OV, Morrell CH, Longo DL, Kashkin VA, et al. (2008) Endogenous sodium pump inhibitors and age-associated increases in salt sensitivity of blood pressure in normotensives. Am J Physiol Regul Integr Comp Physiol 294: R1248-1254.

31. Fedorova OV, Lakatta EG, Bagrov AY, Melander O (2015) Plasma level of the endogenous sodium pump ligand marinobufagenin is related to the saltsensitivity in men. J Hypertens 33: 534-541. 
32. Falkner B, Hulman S, Kushner H (1992) Hyperinsulinemia and blood pressure sensitivity to sodium in young blacks. J Am Soc Nephrol 3: 940-946.

33. Palacios C, Wigertz K, Martin BR, Jackman L, Pratt JH, et al. (2004) Sodium retention in black and white female adolescents in response to salt intake. $J$ Clin Endocrinol Metab 89: 1858-1863.

34. Tiffin N, Meintjes A, Ramesar R, Bajic VB, Rayner B (2010) Computational analysis of candidate disease genes and variants for salt-sensitive hypertension in indigenous Southern Africans. PLoS One 5: e12989.

35. Unakar NJ, Johnson M (1994) Lenticular alterations in hypertensive rats. Exp Eye Res 59: 645-652.

36. Pavlovic D (2014) The role of cardiotonic steroids in the pathogenesis of cardiomyopathy in chronic kidney disease. Nephron Clin Pract 128: 11-21.

37. Crespo CJ, Loria CM, Burt VL (1996) Hypertension and other cardiovascular disease risk factors among Mexican Americans, Cuban Americans, and Puerto Ricans from the Hispanic Health and Nutrition Examination Survey. Public Health Rep 111: 7-10.

38. Zevallos J, Santiago F, González J, Rodríguez A, Pericchi L, et al. (2015) Burden of stroke in Puerto Rico. Int J Stroke 10: 117-119.
39. Rodríguez-Sargent C, Estapé ES, Rodríguez-Santiago A, Ramos VL, Irizarry JE, et al. (1990) Lenticular rubidium uptake and plasma renin activity in weanling "cataract-prone" salt-sensitive rats. Hypertension 15: 144-148.

40. Kawarazaki W, Fujita T (2013) Aberrant Rac1-mineralocorticoid receptor pathways in salt-sensitive hypertension. Clin Exp Pharmacol Physiol 40: 929936.

41. Hodes A, Lichstein D (2014) Natriuretic hormones in brain function. Frontiers in Endocrinology 5: 201

42. Sanada H, Jones JE, Jose PA (2011) Genetics of salt-sensitive hypertension. Curr Hypertens Rep 13: 55-66.

43. Song H, Karashima E, Hamlyn JM, Blaustein MP (2014) Ouabain-digoxin antagonism in rat arteries and neurones. J Physiol 592: 941-969.

44. Pathai S, Shiels PG, Lawn SD, Cook C, Gilbert C (2013) The eye as a model of ageing in translational research--molecular, epigenetic and clinical aspects. Ageing Res Rev 12: 490-508. 